\title{
Pneumatic-Combustion Hybrid Engine: A Study of the Effect of the Valvetrain Sophistication on Pneumatic Modes
}

\author{
P. Brejaud, A. Charlet, Y. Chamaillard, A. Ivanco and P. Higelin* \\ Université d'Orléans - PRISME/EPM, 8 rue Léonard de Vinci, 45072 Orléans Cedex 09 - France \\ email: pascal.brejaud@univ-orleans.fr - alain.charlet@univ-orleans.fr - yann.chamaillard@univ-orleans.fr \\ andrej.ivanco@univ-orleans.fr - pascal.higelin@univ-orleans.fr \\ * Corresponding author
}

\begin{abstract}
Résumé - Moteur hybride pneumatique: une étude de l'effet de la complexité de la distribution sur les modes pneumatiques - Bien que le rendement total d'un moteur à combustion interne soit élevé, ce potentiel ne peut être pleinement exploité sur une automobile: dans les conditions réelles d'utilisation, la charge moteur moyenne (et donc le rendement) est souvent faible. De plus, l'énergie cinétique en phase de freinage est totalement dissipée sous forme de chaleur. Cet article présente un concept de moteur hybride pneumatique, et les cycles thermodynamiques associés, capable de stocker de l'énergie (et de la réutiliser) sous forme d'air comprimé. Le concept est adaptable au moteur à allumage commandé aussi bien qu'au moteur à allumage par compression. Dans tous les cas, les gains de consommation sont étroitement liés à la performance de la distribution. Cette étude se focalise sur les deux modes pneumatiques majeurs: le mode pompe pneumatique et le mode moteur pneumatique. Pour chacun d'entre eux, trois différents types de distribution sont envisagés: type 4 temps, type 4 temps avec un arbre à came débrayable et type 2 temps entièrement variable.

Un modèle cinématique de l'actuateur de la soupape de charge est présenté et implémenté dans un modèle zéro-dimensionnel du moteur hybride pneumatique. Les résultats issus de la simulation, pour chacun des 2 modes pneumatiques, et pour chacun des 3 types de distribution envisagés, sont présentés avec pour objectif d'identifier la meilleure configuration de la distribution, et de montrer l'impact de la cinématique de l'actuateur de la soupape de charge sur les performances de la machine. Les compromis entre la complexité de la distribution et les gains de consommation sont présentés dans chacun des cas.
\end{abstract}

Abstract - Pneumatic-Combustion Hybrid Engine: A Study of the Effect of the Valvetrain Sophistication on Pneumatic Modes - Although internal combustion engines display high overall maximum global efficiencies, this potential cannot be fully exploited in automotive applications: in real conditions, the average engine load (and thus efficiency) is quite low and the kinetic energy during a braking phase is lost. This work presents a hybrid pneumatic-combustion engine and the associated thermodynamic cycles, which is able to store and recover energy in the form of compressed air. The study focuses on the two major pneumatic modes: pneumatic pump mode and pneumatic motor mode. For each of them, three valvetrain technologies are considered: 4-stroke mode, 4-stroke mode with one camshaft disengaged, and 2-stroke fully variable.

The concept can be adapted to SI or CI engines. In any case the valvetrain technology is the key to best fuel economy. A kinematic model of the charging valve's actuator is introduced, and implemented in a quasi dimensional model of the pneumatic-combustion hybrid engine. Simulation results are presented for each pneumatic mode, for each valvetrain technology, in order to determine the best valve train configuration, and to show the impact of the kinematic valve actuator on the performance of the engine The tradeoffs between valvetrain sophistication and fuel economy will be presented for each case. 


\section{DEFINITIONS, ACRONYMS, ABBREVIATIONS}

\author{
TDC Top Dead Center \\ BDC Bottom Dead Center \\ SPC Specific Pump Consumption \\ PME Pneumatic Motor Efficiency
}

\section{SYMBOLS}

$\Delta \theta \quad$ Valve opening duration in Crack angle (rad)

$\Delta \theta \mathrm{e} \quad$ Duration of valve acceleration's crenels ( $\mathrm{rad})$

$\Delta \theta \mathrm{c} \quad$ Angular duration of the maximum lift ( $\mathrm{rad})$

$\gamma \quad$ Valve acceleration as function as time $\left(\mathrm{m} / \mathrm{s}^{2}\right)$

$\gamma_{\theta} \quad$ Valve acceleration as function as crank angle $\left(\mathrm{m} / \mathrm{rad}^{2}\right)$

$\gamma_{\max }$ Maximum valve acceleration $\left(\mathrm{m} / \mathrm{s}^{2}\right)$

$v_{\max }$ Maximum valve speed $(\mathrm{m} / \mathrm{s})$

$l_{\max } \quad$ Desired maximum valve lift (m)

$l_{\text {effective }}$ Effective lift reached by the valve $(\mathrm{m})$

$\omega \quad$ Angular crankshaft speed ( $\mathrm{rad} / \mathrm{s})$

$P_{u} \quad$ Pressure Upstream the throat $(\mathrm{Pa})$

$P_{d} \quad$ Pressure Downstream the throat $(\mathrm{Pa})$

$r_{c} \quad$ Pressure ratio at the throat

$W_{i} \quad$ Indicated work (J/cycle)

$m_{\text {air tank }}$ Air mass sent or received from the air tank per cycle (g/cycle)

\section{INTRODUCTION}

The concept of pneumatic hybridization is based on a traditional internal combustion engine in the cylinder head of which a duct and an additional valve are added $[1,2]$. This valve, called the charging valve, connects the combustion chamber to an air tank (see Fig. 1)

With this concept, in addition to the conventional internal combustion engine operations (SI or CI), several new operating modes are made possible [3]. Two of those new thermodynamic cycles have to be singled out: pneumatic motor, and pneumatic pump mode.

But to make the new cycles effective, the opening and closing timings of the charging valve have to be variable with engine revolution speed and tank pressure. Therefore the charge valve has to be governed by a fully variable actuator, symbolized by a hydraulic jack in Figure 1 .

In the case of inlet and exhaust valve, the problem is different and several valve-train technologies can be proposed:

The first solution is to use actuators similar to the charging valve unit. This solutions leads to the best flexibility, but creates heavy changes on the cylinder head. This solution is called fully variable valvetrain, and allows 2 -stroke cycles.

A second configuration is to use traditional camshafts to govern the opening and closing of inlet and exhaust valves.

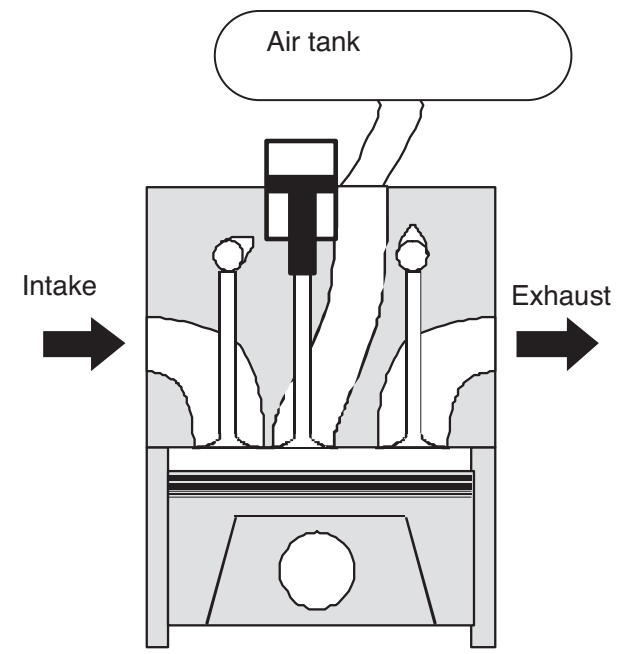

Figure 1

Pneumatic hybridization concept.

This solution, called traditional valvetrain, leads to the minimum technological changes in the cylinder heads, but the thermodynamic cycles have to be 4-stroke cycles and timings, for opening and closing, cannot be shifted at best.

In order to limit this major drawback a third intermediate configuration is proposed, consisting in disengaging one camshaft (inlet or exhaust) if needed. This solution will be called inlet-off if the inlet camshaft is disengaged and exhaust-off if the exhaust camshaft is disengaged.

In this paper, the idealized cycles of the two major pneumatic operating modes for the three cases of valvetrain proposed will be presented. Then, a kinematic model of the charging valve actuator will be introduced, and used to implement a quasi dimensional model of the engine. The results of numerical simulation will be presented in order to determine the best valve train configuration for each mode, and to show the important impact of the valve actuator kinematics on the performance of the engine.

\section{PNEUMATIC PUMP MODE}

One of the largest weaknesses of internal combustion engines is that the thermodynamic cycle cannot be reversed. As a result the kinetic energy of a vehicle using a conventional internal combustion engine cannot be recovered into chemical energy during braking situations.

The pneumatic pump cycle can produce negative torque during braking situations, and convert part of the kinetic energy to potential energy in the form of pressurized air pumped into the air tank. 


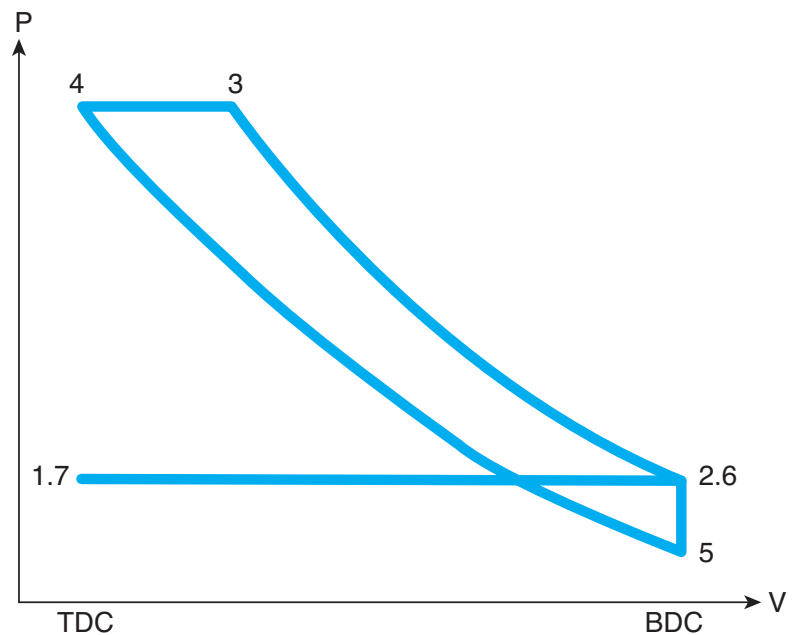

Figure 2

Idealized $p$ - $V$ diagram of a 4-stroke pneumatic pump cycle with inlet and exhaust-on.

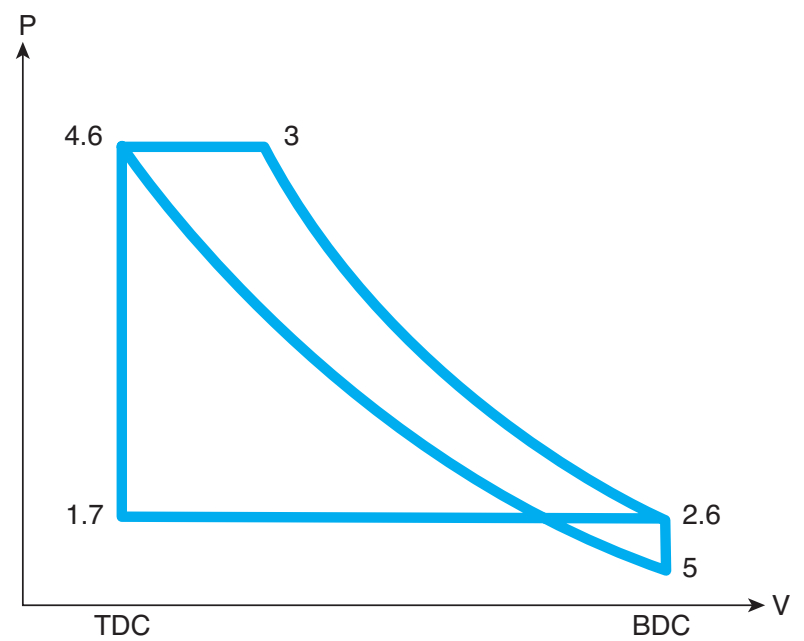

Figure 3

Idealized $p-V$ diagram of 4 -stroke pneumatic pump cycle with exhaust-off and inlet-on.

\subsection{Four-Stroke Pump Cycle}

The 4-stroke pneumatic pump cycle is obtained with traditional camshaft systems for inlet and exhaust valves, thus the entire cycle is performed within two crankshaft revolutions. Figure 2 displays the idealized $p$ - $V$ diagram:

- Intake: the intake valve opens at point 1 (TDC). From 1 to 2 the cylinder is filled with fresh air from the intake manifold. The valve is closed at point 2 (BDC). The pressure is constant and equals atmospheric pressure at full throttle condition.

- Compression: from 2 to 3 all the valves are closed, and the charge is compressed up to tank pressure. At point 3, the cylinder pressure equals the tank pressure, thus Point 3 is varying from cycle to cycle with tank pressure.

- Air tank charging: from 3 to 4 , the charging valve is open. The air tank charging is performed at nearly constant pressure.

- Expansion: form 4 to 5, all the valves are closed, the compressed air that could not be pushed into the air tank expands until the piston reaches BDC. Because the mass of air inside the cylinder at the beginning of expansion is lower than at point 2 , the pressure at point 5 (BDC) is necessarily lower than atmospheric pressure.

- Exhaust: the exhaust valve opens at point 5. Because the pressure is lower than atmospheric pressure, the cylinder is at first filled at constant volume with gases from the exhaust manifold until pressure equals one atmosphere, which is reached at point 6 . Then the piston is moving up to the TDC and the gases are expelled. It is obvious, that clearance volume at point 1 can contain burned gases, until the exhaust manifold is completely filled with fresh air.

\subsection{Four-Stroke Pump Cycle Exhaust-Off}

This cycle is obtained with traditional camshafts and with the exhaust camshaft disengaged (Fig. 3). Points 1 to 5 are similar to Figure 2. But at point 5, the exhaust valve remains closed, so from 5 to 6 the air is compressed again up to tank pressure. At point 6 , inlet valve opens, and the pressure drops to atmospheric pressure. In this cycle there is no suction of burned gases from the exhaust manifold.

\subsection{Two-Stroke Pump Cycle}

The 2-stroke pneumatic cycle, is possible only with a fully variable valvetrain. The full cycle is completed within one crankshaft revolution. Figure 4 displays the idealized $p-V$ diagram:

- Intake: the intake valve opens at point 1 . From 1 to 2 , the cylinder is filled with fresh air from the intake manifold. Point 2 is located at BDC if maximum air mass is needed.

- Compression: from 2 to 3 all the valves are closed, and the air charge is compressed up to tank pressure thus point 3 is varying from cycle to cycle with air tank pressure.

- Air tank charging: from 3 to 4 , the charging valve is open. The end of compression stroke is used to expel compressed air from the cylinder to the tank. 


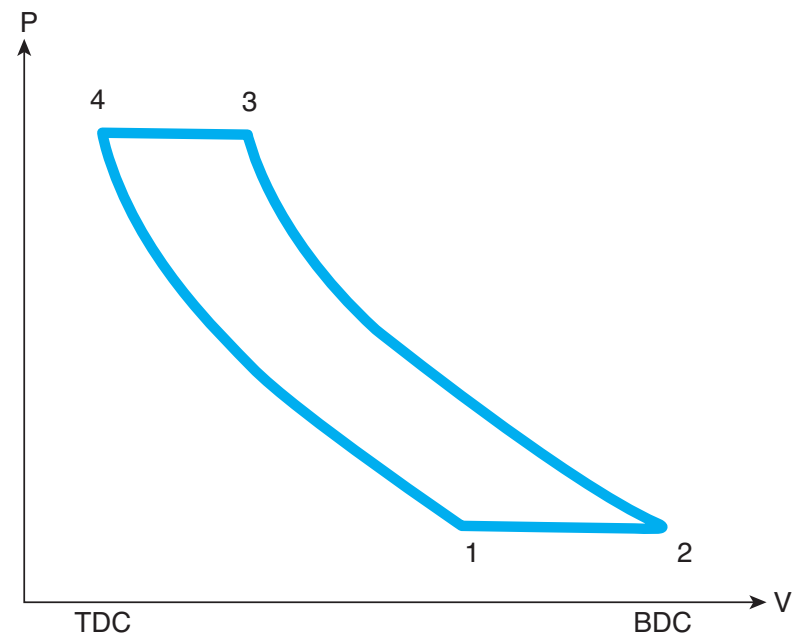

Figure 4

Idealized $p$ - $V$ diagram of a 2 -stroke pneumatic pump cycle.

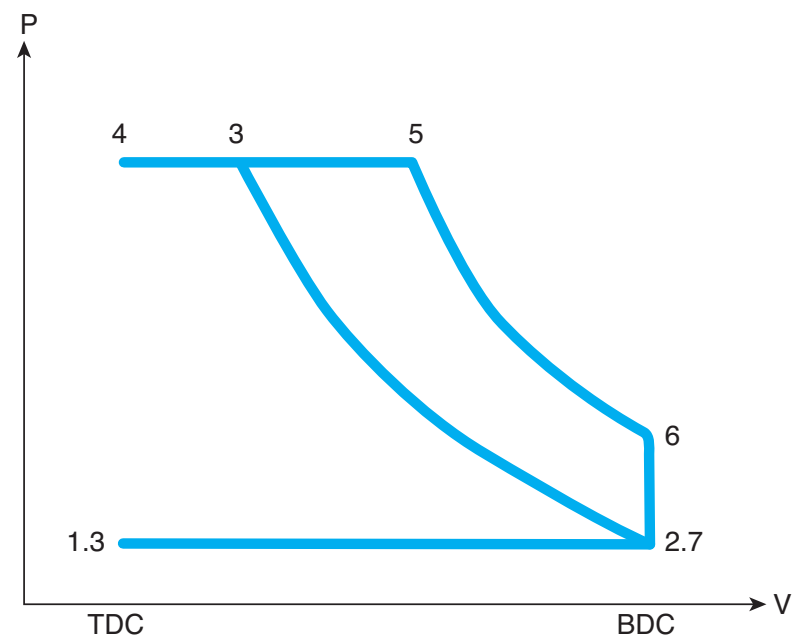

Figure 5

Idealized $p$ - $V$ diagram of 4-stroke pneumatic motor with inlet and exhaust-on.
- Expansion: from 4 to 1 all the valves are closed and the compressed air that could not be pushed into the air tank expands to atmospheric pressure.

\section{PNEUMATIC MOTOR MODE}

The hybrid pneumatic-combustion engine can produce torque from $0 \mathrm{rpm}$, operating as a pneumatic engine powered by the high pressure tank. This mode allows to start and drive the car from a null speed up to around $20 \mathrm{~km} / \mathrm{h}$ [4]. This characteristic allows suppressing idling phases and reduces the use of the conventional combustion mode. A fuel saving up to $40 \%$ can be reached depending on the driving cycle [4-6].

\subsection{Four-Stroke Pneumatic Motor Cycle}

The 4-stroke pneumatic motor cycle is obtained with traditional camshaft systems for inlet and exhaust valves. The entire cycle is performed within two crankshaft revolution. Figure 5 displays the idealized $p$ - $V$ diagram:

- Intake: the intake valve opens at point 1 . The cylinder is filled, form 1 to 2, with fresh air at atmospheric pressure.

- Compression: from 2 to 3, all the valves are closed, and the air is compressed up to the air tank pressure. Point 3 is varying from cycle to cycle depending on the tank pressure level.

- Cylinder charging: from 3 to 5 through 4 (TDC), the charge valve is open, so that the pressure inside the cylinder is maintained at tank pressure level.
- Expansion: from 5 to 6 all the valves are closed, the air expands and reaches at least a pressure higher than atmospheric pressure.

- Exhaust: exhaust valve opens at point 6 (BDC), pressure drops down to atmosphere, and the gases are expelled as the piston joins TDC.

\subsection{Four-Stroke Pneumatic Cycle Inlet-Off}

This cycle is obtained with traditional camshafts except that the inlet camshaft is disengaged. Figure 6 displays the idealized $p-V$ diagram:

- Cylinder charging: at point 1 (TBC), the charging valve opens. The air tank discharges into the cylinder between 1 and 2 where the cylinder pressure reaches the tank pressure. From 2 to 3 the discharge process is continued at a constant pressure.

- Expansion: from 3 to 4 all the valves are closed and the air charge expands. The timing of charging valve closure can be optimized in order to superimpose point 4 and 5 . In this case, a full expansion of the air charge is obtained.

- Exhaust: the exhaust valve opens at point 4. From 4 to 5 , cylinder discharges into the exhaust pipe. From 5 to 6 , the exhaust stroke expels the remaining air into the exhaust manifold.

- Lost strokes: during 6- 7 - 1, all the valves are closed. The air first expands from 6 to 7, and then is compressed from 7 to 1 where the cylinder pressure reaches atmospheric pressures. 


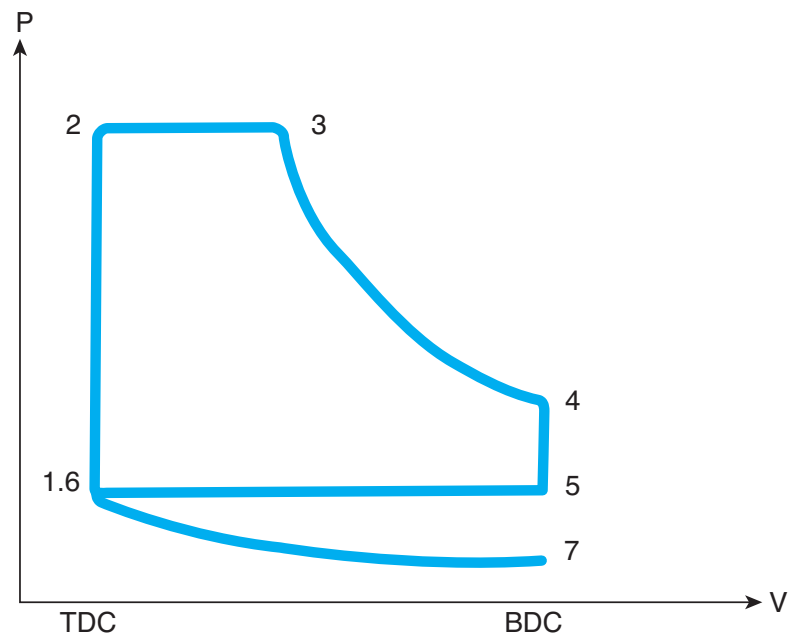

Figure 6

Idealized $p$ - $V$ diagram of 4 -stroke pneumatic motor with inlet-off and exhaust-on.

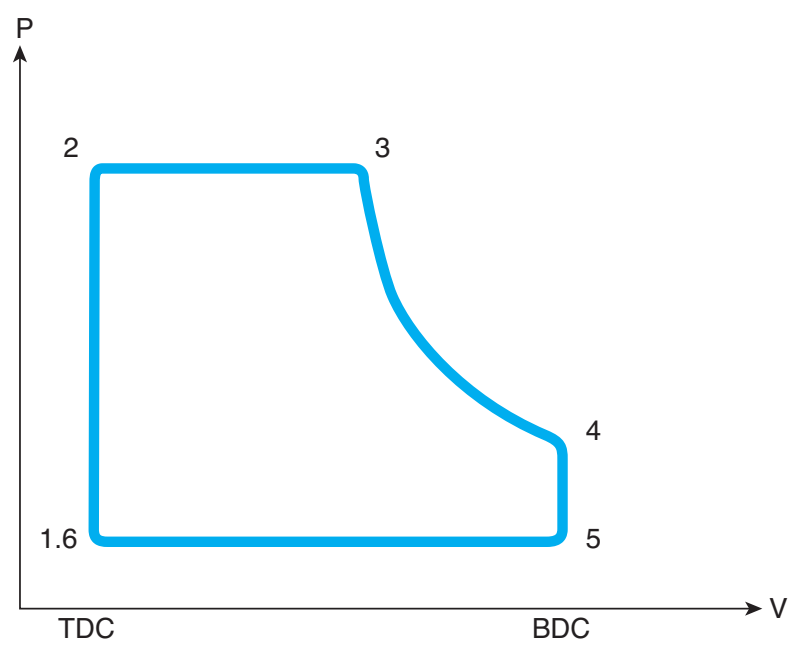

Figure 7

Idealized $p$ - $V$ diagram of 2-stroke pneumatic motor.

\subsection{Two-Stroke Pneumatic Cycle}

The 2-stroke pneumatic motor cycle, is possible only with a fully variable valvetrain. Figure 7 displays the idealized $p-V$ diagram.

The cycle is similar to the 4-stroke pneumatic cycle inletoff (Sect. 2.2 and Fig. 6), from point 1 to 6. The lost stokes sequence 6-7-1 is removed. The cycle is performed during one crankshaft revolution.

\section{CHARGING VALVE MODEL}

\subsection{Charging Valve Kinematics}

All idealized cycles presented in this paper suppose an instantaneous opening and closure of the valve, thus an infinite acceleration. In order to simulate the performance of each cycle presented in this paper in realistic conditions [7], it is necessary to develop a kinematic model of the charging valve, which will be applied to inlet and exhaust valves in the case of cycles with fully variable valvetrain (2-stroke pneumatic motor and pump).

In order to be independent of a specific technology $[6,8$ 11], a simple kinematic model of the charging valve has been developed, as displayed in Figure 8.

The idea of this model is to suppose that the actuator generate crenels of constant positive or negative acceleration [8] $\left( \pm \gamma_{\max }\right)$, during same angular durations $(\Delta \theta \mathrm{e})$, to generate the desired valve lift $\left(l_{\max }\right)$.

It is important to note that for most actuators, the acceleration $\pm \gamma_{\max }$ produced is independent from engine speed. Then $\gamma_{\theta}$ the acceleration expressed as a function of crank angle is not constant and depends on the angular speed of the crankshaft. If the engine speed can be considered constant during the valve lift:

$$
\gamma=\gamma_{\theta} \cdot \omega^{2}
$$

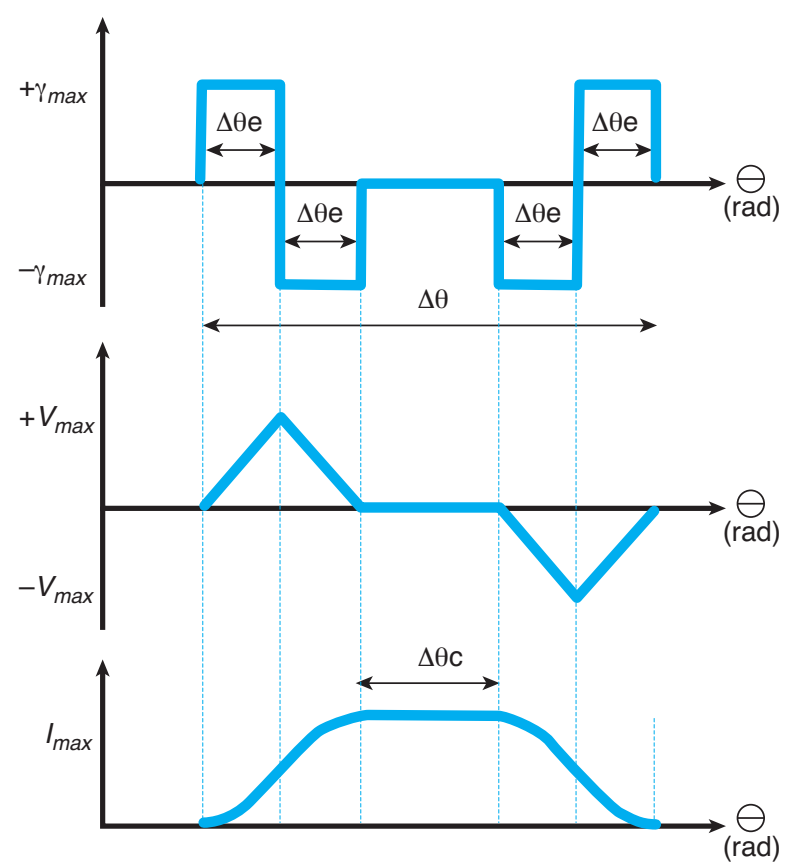

Figure 8

Kinematic model of charging valve. Acceleration, speed and lift of the valve versus crank angle. 
Figure 8 yields two simple relations:

$$
\begin{gathered}
v_{\text {max }}=\gamma_{\max } \cdot \frac{\Delta \theta \mathrm{e}}{\omega} \\
l_{\text {max }}=\gamma_{\text {max }} \cdot\left(\frac{\Delta \theta \mathrm{e}}{\omega}\right)^{2}
\end{gathered}
$$

Now, two cases have to be distinguished:

- If $\Delta \theta \geq 4 \omega \sqrt{\frac{l_{\max }}{\gamma_{\max }}}$, which is equivalent to $\Delta \theta c \geq 0$, then the valve reaches the desired lift $l_{\max }$ within an angular duration of acceleration crenel $\Delta \theta \mathrm{e}=\omega \sqrt{\frac{l_{\max }}{\gamma_{\max }}}$

- If $\Delta \theta<4 \omega \sqrt{\frac{l_{\max }}{\gamma_{\max }}}$ which leads to $\Delta \theta c=0$ then the valve does not reach the desired lift $l_{\max }$. The angular duration of the acceleration crenel is then $\Delta \theta \mathrm{e}=\frac{\Delta \theta}{4}$, and the effective lift is given by Equation (4):

$$
l_{\text {effective }}=\gamma_{\max } \cdot\left(\frac{\Delta \theta}{4 \omega}\right)^{2}
$$

Equation (3) shows that to produce a large lift, a high acceleration $\gamma_{\max }$, a high angular duration $\Delta \theta \mathrm{e}$ or slow engine speed $\omega$ is needed.

These ideal conditions cannot be always honored on a pneumatic hybrid engine. For example, if the desired max lift is $5 \mathrm{~mm}, \Delta \theta=20^{\circ}$ with $\Delta \theta \mathrm{e}=5^{\circ}$ (max duration available), $\omega=3000$ RPM, the needed acceleration given by Equation (3) is $64800 \mathrm{~m} / \mathrm{s}^{2}$.

Today's actuators cannot produce such a high acceleration. A typical value for maximum acceleration is near $3000 \mathrm{~m} / \mathrm{s}^{2}$. For comparison, a traditional camshaft, for an engine speed of $7000 \mathrm{RPM}$ produces acceleration around $10000 \mathrm{~m} / \mathrm{s}^{2}$.

The impact of the quite slow opening and closing of the charging valve has been evaluated with a quasi-dimensional model. This model implements the aforementioned kinematic charging valve model, in order to determine and compare the performances of each cycle taking into account the acceleration constraint.

\subsection{Mass Flow Rate}

The mass flow rate through the vale is calculated with the classical Barré de Saint Venant equation, using the pressure ratio at the throat. Four cases must be distinguished. The flow can be in the forward or reverse direction (back flow) and it can be sub or supersonic. Equation (5) presents the pressure critical ratio $\left(r_{c}\right)$ at the throat which determines the type of the flow. If the pressure drop is lower than the critical ratio, the flow is supersonic, otherwise the flow is subsonic:

$$
r_{c}=\frac{P_{u}}{P_{d}}=\left(\frac{2}{\gamma+1}\right)^{\frac{\gamma}{\gamma-1}}
$$

Equation (6) represents the mass flow in the supersonic case. Equation (7) presents the mass flow in the subsonic case. $C d$ is the discharge coefficient and $A r$ is the area of the singularity. This area is calculated from the valve lift:

$$
\begin{gathered}
\frac{d m}{d t}=C d \cdot A r \cdot \frac{P_{u}}{\sqrt{r \cdot T_{u}}} \cdot \gamma^{0.5} \cdot\left(\frac{2}{\gamma+1}\right)^{\frac{\gamma+1}{2 \cdot(\gamma-1)}} \\
\frac{d m}{d t}=C d \cdot A r \cdot\left(\frac{P_{u}}{\sqrt{r \cdot T_{u}}}\right) \cdot\left(\frac{P_{u}}{P_{d}}\right)^{\frac{1}{\gamma}} \cdot \sqrt{\left(\frac{2 \cdot \gamma}{\gamma-1}\right) \cdot\left(1-\left(\frac{P_{u}}{P_{d}}\right)^{\frac{\gamma-1}{\gamma}}\right)}
\end{gathered}
$$

\section{QUASI-DIMENSIONAL ENGINE MODEL}

Figure 9 shows a schematic view of the model. The model is a quasi-dimensional model [2] where volumes (tank, intake and exhaust pipes) are connected together via flow singularities (valve, throttle, etc.). Due to the nature of the model, gas dynamics has been neglected inside pipes.

CYLINDER - The cylinder is the central part of the system. It exchanges work, heat and mass with the outside. The first law of thermodynamics can be written as follows:

$$
d U=\delta W+\delta Q+h_{i} \cdot d m_{i}+h_{o} \cdot d m_{o}
$$

where $U$ is the internal energy, $W$ is the work generated by the moving walls, $Q$ is the total heat, $m$ the mass and $h$ the enthalpy. $i$ indicates the intake flow, $o$ indicates the outlet flow.

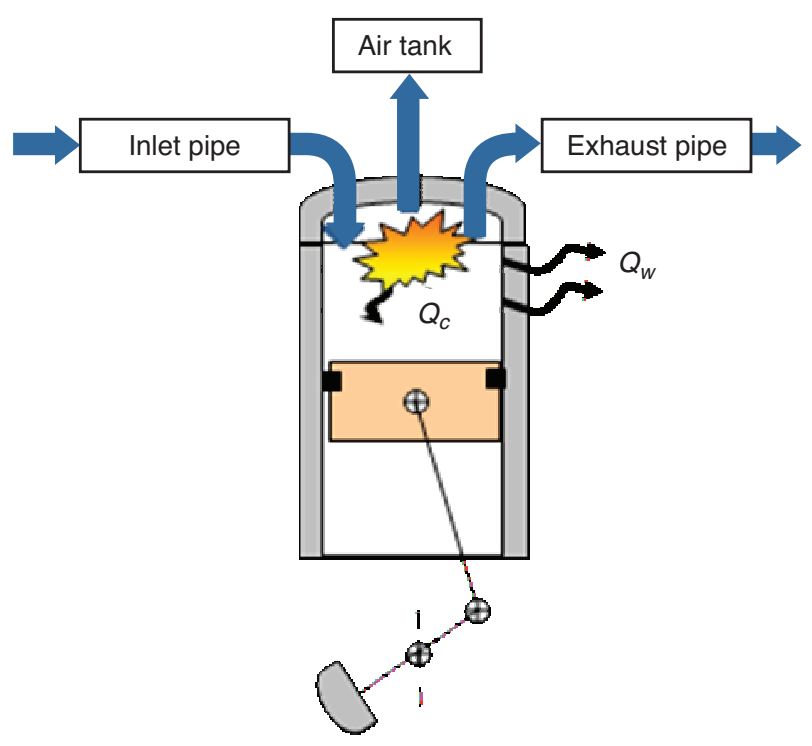

Figure 9

Schematic view of the model of the hybrid pneumaticcombustion engine. 
Continuity equation:

$$
d m=d m_{i}+d m_{o}
$$

The total heat $Q$ is the sum of a combustion heat $Q c$ given by a Wiebe [12] model, and heat loss $Q w$ given by a standard Woshni [13] model:

$$
\delta Q=\delta Q c+\delta Q w
$$

For an ideal gas, with a constant composition, the internal energy is:

$$
d U=m \cdot c_{v} \cdot d T+c_{v} \cdot T \cdot d m
$$

Using Equation (8) and Equation (11) the following expression can be obtained:

$$
d T=\frac{\delta W+\delta Q+d h_{i}+d h_{o}-c_{v} \cdot T \cdot d m}{m \cdot c_{v}}
$$

The volume is determined from the engine geometry. The mass inside the cylinder is determined by integrating the mass flow through each valve (Eq. 5-7) and the temperature by integrating Equation (12). Then, the cylinder pressure is calculated with the ideal gas law:

$$
P=\frac{m \cdot r \cdot T}{V}
$$

AIR TANK, INLET AND EXHAUST PIPES - These components are similar to the cylinder except that the volume is constant. So Equation (12) becomes:

$$
d T=\frac{\delta Q+d h_{i}+d h_{o}-c_{v} \cdot T \cdot d m}{m \cdot c_{v}}
$$

\section{SIMULATION RESULTS}

The simulated engine is a typical single cylinder engine (cylinder volume around $400 \mathrm{~cm}^{3}$ ) with 5 valves including one charging valve. The hydraulic charging valve diameter is around $15 \mathrm{~mm}$.

The total cylinder head area being limited, the charging valve must be chosen sufficiently small to avoid compromising conventional operation. This rather small valve dimension, added to a quite slow valve actuator may lead to serious differences between real and idealized cycles. In order to approach real cycles as near as possible, each cycle has been simulated with a quasi-dimensional model implementing the kinematic model of the charging valve actuator.

\subsection{Pneumatic Pump Mode}

Figures 11-13 display the simulated $p-V$ diagram of respectively a 4-stroke pump, 4-stroke pump mode with exhaust-off, and 2-stroke full variable pump mode. These simulations have been performed with an air tank pressure of 5 bars, an engine speed of 1500 RPM, and a maximum valve acceleration of $3000 \mathrm{~m} / \mathrm{s}^{2}$.
For each mode, the optimum opening timing for charging valve has been determined with a constant closure at TDC. In the specific case of the 2-stroke mode, Inlet Valve Closure and Opening timings were optimized too. The criterion used was to maximize the air sent to the air tank, without worrying about Indicated Work. Indeed, during pneumatic pump mode, energy can be considered without any cost, as there is more energy available than can be stored during each braking phase. Table 1 shows the optimized timings, expressed in crank angle, and Figure 10 displays the effect of the opening timing in the specific case of 4-stroke pneumatic pump mode. (Reference angle is for end exhaust/start inlet TDC.)

TABLE 1

Pneumatic pump optimum angles for the opening and the closure of valves

\begin{tabular}{l|c|c|c}
\hline & 4-stroke & $\begin{array}{c}\text { 4-stroke } \\
\text { exhaust-off }\end{array}$ & $\begin{array}{c}\text { 2-stroke } \\
\text { full variable }\end{array}$ \\
\hline Inlet open & $-10^{\circ}$ & $710^{\circ}$ & $35^{\circ}$ \\
\hline Inlet close & $190^{\circ}$ & $190^{\circ}$ & $190^{\circ}$ \\
\hline Charging open & $310^{\circ}$ & $310^{\circ}$ & $310^{\circ}$ \\
\hline Charging close & $360^{\circ}$ & $360^{\circ}$ & $360^{\circ}$ \\
\hline Exhaust open & $530^{\circ}$ & $\mathrm{x}$ & $\mathrm{x}$ \\
\hline Exhaust close & $10^{\circ}$ & $\mathrm{x}$ & $\mathrm{x}$ \\
\hline
\end{tabular}

Table 2 displays the indicated work, the pumped air mass sent to the air tank, and the Specific Pump Consumption (SPC) defined by Equation (15) for each simulated mode. It can be seen that the lower the SPC is; the best the conversion from mechanical energy to pneumatic potential energy is:

$$
\operatorname{SPC}(\mathrm{J} / \mathrm{g})=\frac{W i(\mathrm{~J} / \text { cycle })}{m_{\text {air.tank }}(\mathrm{g} / \text { cycle })}
$$

A comparison between simulated cycles (Fig. 11-13) and idealized cycles (Fig. 2-4) shows that the shapes are similar expect during the charging valve opening. During this period, Figure 11 displays a peak that does not exist on idealized cycle. The major cause of this peak is the small charging valve size that creates an obstruction to the air flow, and a minor cause is the slow valve opening due to limited maximum acceleration.

TABLE 2

Pneumatic pump mode results

\begin{tabular}{l|c|c|c}
\hline & 4-stroke & $\begin{array}{c}\text { 4-stroke } \\
\text { exhaust- } \\
\text { off }\end{array}$ & $\begin{array}{c}2 \text {-stroke } \\
\text { full } \\
\text { variable }\end{array}$ \\
\hline Indicated work (J/cycle) & 73.1 & 74.1 & 62.9 \\
\hline Pumped air mass (g/cycle) & 0.275 & 0.275 & 0.280 \\
\hline SPC (J/g) & 265.9 & 269.6 & 224.6 \\
\hline
\end{tabular}




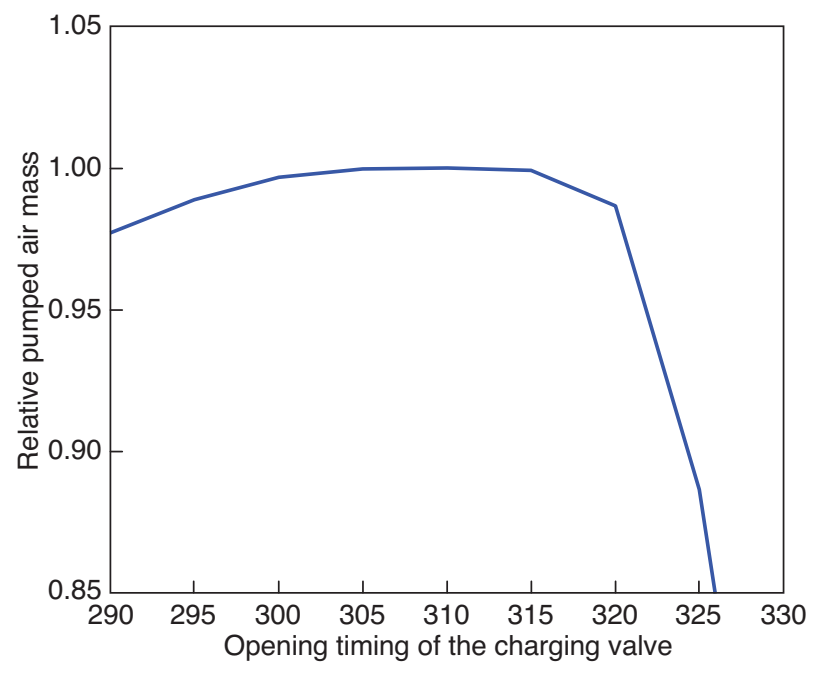

Figure 10

Relative pumped air mass $v s$ opening timing of the charging valve, 4-stroke pump mode. $1500 \mathrm{RPM}-P_{\text {tank }} 0.5 \mathrm{MPa}-$ $\gamma_{\text {max }}=3000 \mathrm{~m} / \mathrm{s}^{2}$.

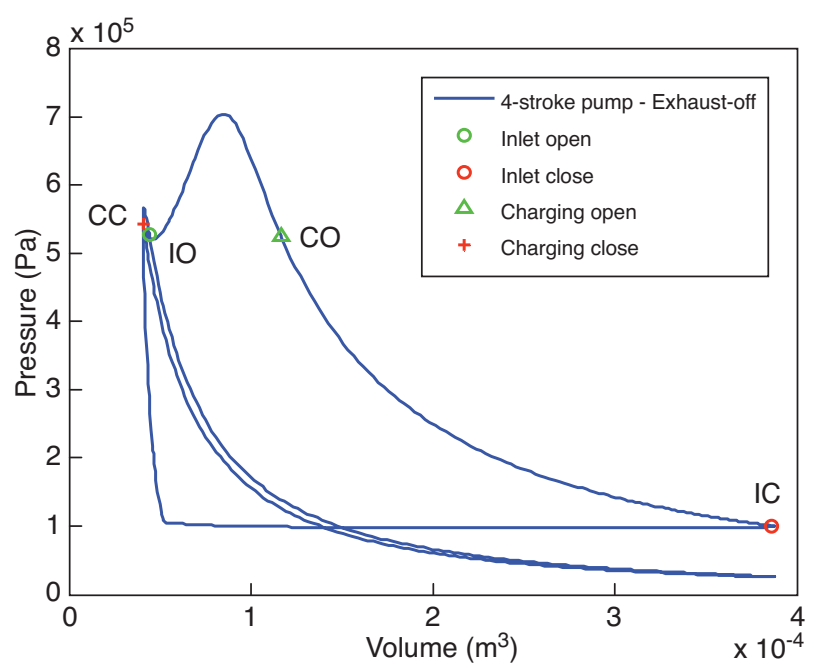

Figure 12

Simulated $p-V$ diagram, 4-stroke pump with exhaust-off. $1500 \mathrm{RPM}-P_{\text {tank }} 0.5 \mathrm{MPa}-\gamma_{\max }=3000 \mathrm{~m} / \mathrm{s}^{2}$.

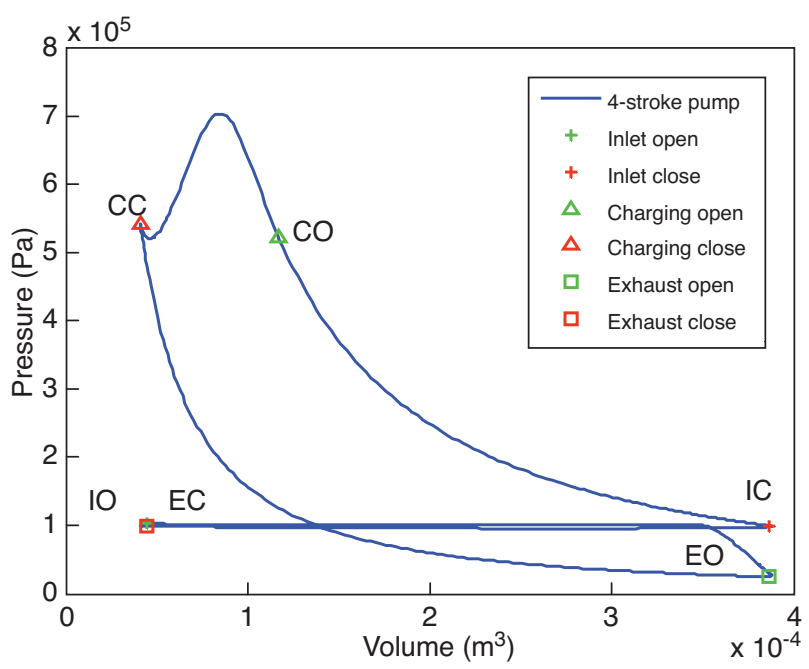

Figure 11

Simulated $p$ - $V$ diagram, 4-stroke pump mode. 1500 RPM $P_{\text {tank }} 0.5 \mathrm{MPa}-\gamma_{\max }=3000 \mathrm{~m} / \mathrm{s}^{2}$.

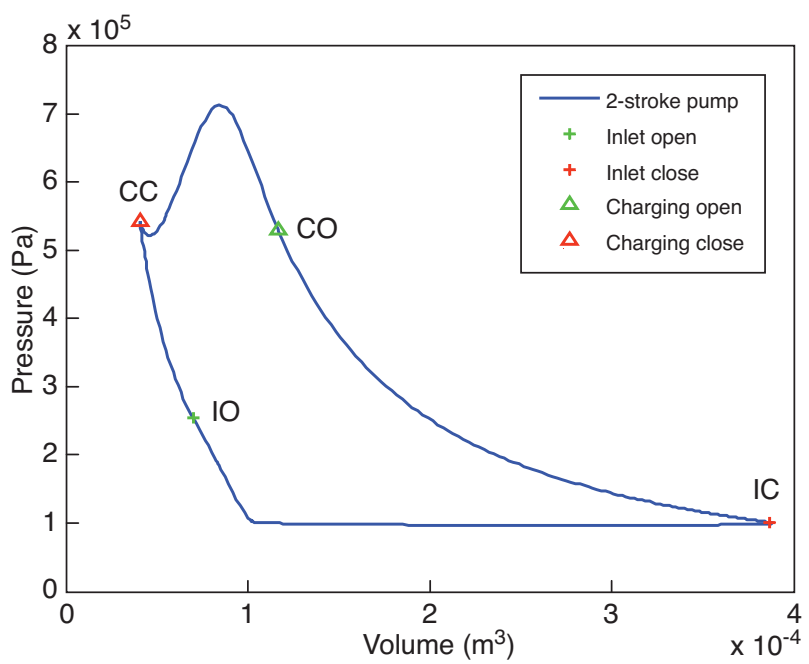

Figure 13

Simulated $p$ - $V$ diagram, 2-stroke pump full variable. $1500 \mathrm{RPM}-P_{\text {tank }} 0.5 \mathrm{MPa}-\gamma_{\max }=3000 \mathrm{~m} / \mathrm{s}^{2}$.
A comparison between Figure 12 and Figure 3 show that the lost strokes in the simulated diagram are not superimposed. This is caused by heat losses to the wall.

An analysis of Table 2 shows that there is no significant difference between a 4-stroke cycle and a 4-stroke cycle with exhaust-off. The complication generated by a disengagable exhaust camshaft leads to no real benefit. A comparison of numerical results between 2-stroke and 4-stroke mode shows, a SPC improvement of $15 \%$. Furthermore there is a great benefit of using the 2-stroke mode: for a given elapsed time, the number of 2-stroke cycles performed is twice as much compared to 4-stroke mode, therefore providing, for idealized cycles, twice the torque and twice the pumped air mass sent to the tank. However, the cylinder head would be more complicated, and probably cost-unrealistic.

To illustrate the impact of the valvetrain sophistication on the performance of the 4-stroke pump mode, the evolution of the pumped-air-mass as a function of engine speed for several 


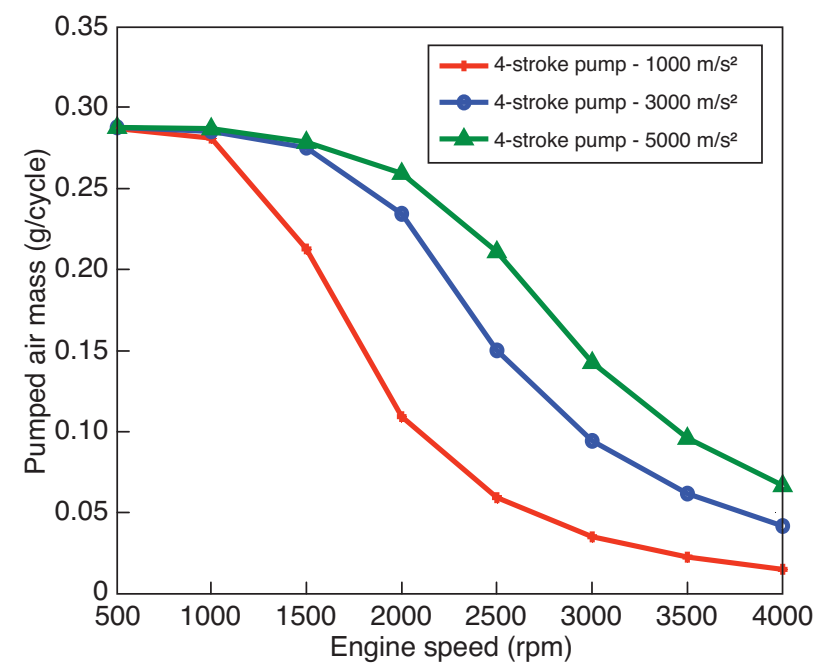

Figure 14

Pumped air mass $v s$ engine speed in 4-stroke pump mode, with charging valve max acceleration of 1000,3000 and $5000 \mathrm{~m} / \mathrm{s}^{2}$.

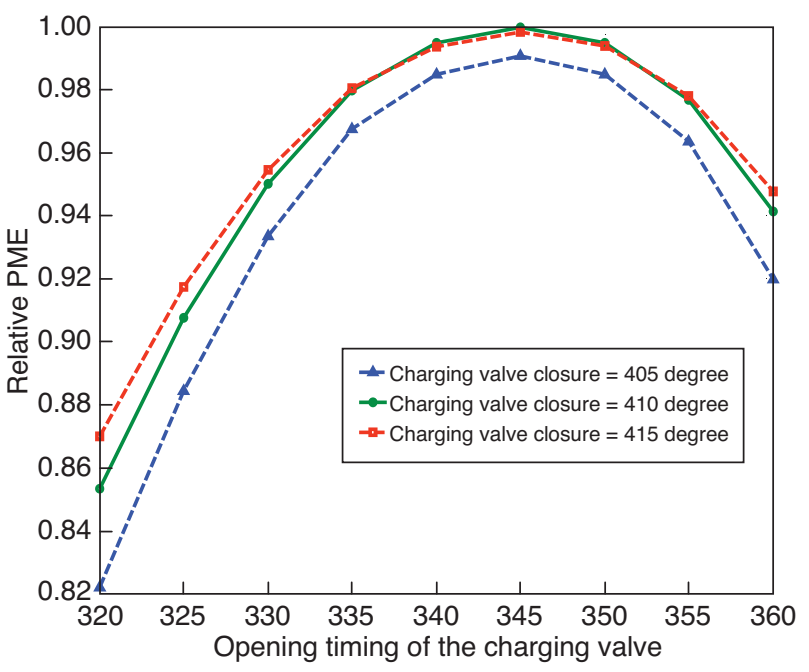

Figure 15

Relative PME $v s$ opening timing of the charging valve, 4-stroke pneumatic motor with inlet-off. $1500 \mathrm{RPM}-P_{\text {tank }} 1 \mathrm{MPa}-$ $\gamma_{\max }=3000 \mathrm{~m} / \mathrm{s}^{2}$. charging valve maximum accelerations has been studied. Figure 14 displays the results. At engine speed lower than 1000 RPM; there is no significant effect of the maximum valve acceleration. But at higher engine speeds, there is a serious impact of the acceleration on performance. Figure 14 demonstrates that the valve train acceleration is the key to best performance at middle and high engine speeds

\subsection{Pneumatic Motor Mode}

Figure 16-18 display the simulated $p-V$ diagram of respectively a 4-stroke pneumatic motor, 4-stroke pneumatic motor with inlet-off, and 2-stroke fully variable pneumatic motor mode. These simulations have been conducted with an air tank pressure of 10 bars, an engine speed of 1500 RPM, and an actuator maximum valve acceleration of $3000 \mathrm{~m} / \mathrm{s}^{2}$.

For each mode, the optimum opening and closing timings for the charging valve has been determined. In the specific case of the 2-stroke mode, exhaust valve closing and opening timings were optimized too. The criterion used was to maximize Pneumatic Motor Efficiency (PME), as defined by Equation (16). Indeed using pneumatic energy is not free, and then should be employed to produce the maximum indicated work. Table 3 gives the timings found in this study, Figure 15 displays the effect of the opening and closure timings in the specific case of 4-stroke pneumatic motor with inlet-off:

$$
\operatorname{PME}(\mathrm{J} / \mathrm{g})=\frac{W i(\mathrm{~J} / \text { cycle })}{m_{\text {air.tank }}(\mathrm{g} / \text { cycle })}
$$

TABLE 3

Opening and closing valve timings for pneumatic motor cycles

\begin{tabular}{l|c|c|c}
\hline & 4-stroke & $\begin{array}{c}\text { 4-stroke } \\
\text { inlet-off }\end{array}$ & $\begin{array}{c}\text { 2-stroke } \\
\text { full variable }\end{array}$ \\
\hline Inlet open & $-10^{\circ}$ & $\mathrm{x}$ & $\mathrm{x}$ \\
\hline Inlet close & $190^{\circ}$ & $\mathrm{x}$ & $\mathrm{x}$ \\
\hline Charging open & $320^{\circ}$ & $345^{\circ}$ & $-15^{\circ}$ \\
\hline Charging close & $440^{\circ}$ & $410^{\circ}$ & $50^{\circ}$ \\
\hline Exhaust open & $530^{\circ}$ & $530^{\circ}$ & $160^{\circ}$ \\
\hline Exhaust close & $10^{\circ}$ & $10^{\circ}$ & $-60^{\circ}$ \\
\hline
\end{tabular}

A comparison between simulated and idealized cycles, shows, in all cases, large differences in shape when the charging valve is opened. The causes are the small charging valve dimension that creates an obstruction to air flow, and the relively low actuator maximum acceleration.

The simulated 2-stroke cycle (Fig. 18) displays a $p$-V diagram with a shape very different from the idealized one (Fig. 7). The optimization of exhaust valve closure leads to an advance of 60 degree before TDC. This large value is the reason of the particular shape of simulated $p-V$ diagram between Exhaust Close (EC) and Charging Open (CO).

An analysis of the numerical results (Tab. 4) leads to the conclusion that the best compromise is to use a 4-stroke engine with only a disengagable inlet camshaft. Table 4 shows that a 2 -stroke cycle would be more efficient (12\%), but the technical complications generated in the cylinder 


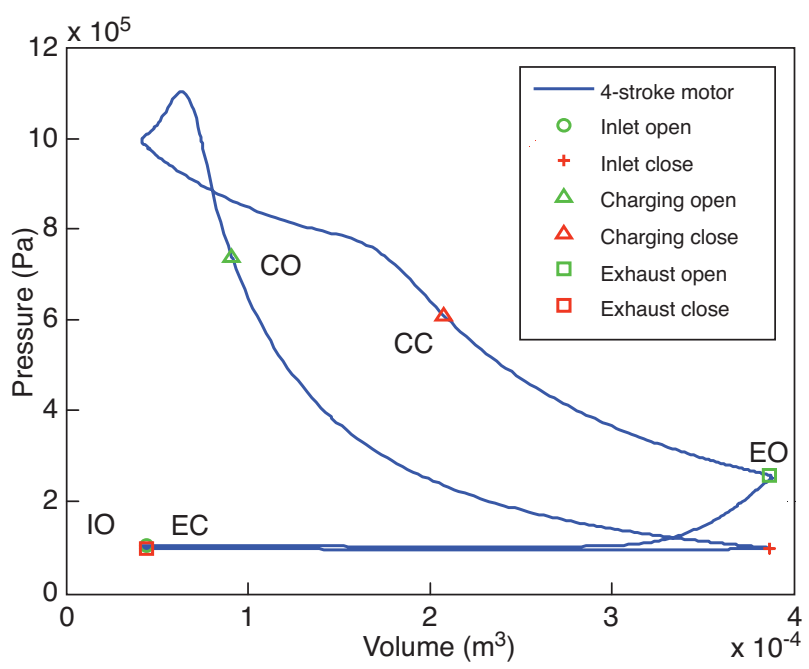

Figure 16

Simulated $p$ - $V$ diagram, 4-stroke pneumatic motor. 1500 RPM $-P_{\text {tank }} 1 \mathrm{MPa}-\gamma_{\max }=3000 \mathrm{~m} / \mathrm{s}^{2}$.

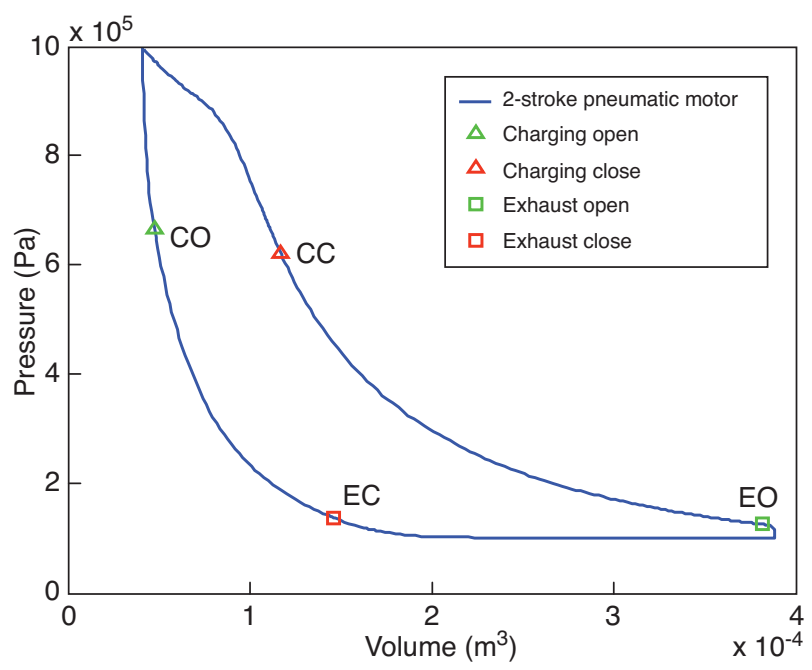

Figure 18

Simulated $p$ - $V$ diagram, 2-stroke pneumatic motor full variable. $1500 \mathrm{RPM}-P_{\text {tank }} 1 \mathrm{MPa}-\gamma_{\max }=3000 \mathrm{~m} / \mathrm{s}^{2}$.

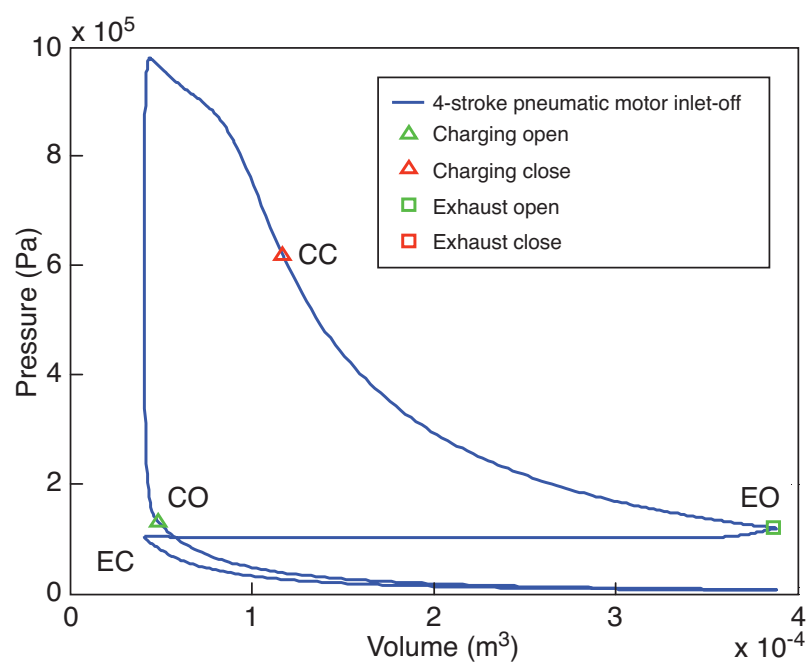

Figure 17

Simulated $p$ - $V$ diagram, 4-stroke pneumatic motor with inletoff. $1500 \mathrm{RPM}-P_{\text {tank }} 1 \mathrm{MPa}-\gamma_{\max }=3000 \mathrm{~m} / \mathrm{s}^{2}$.

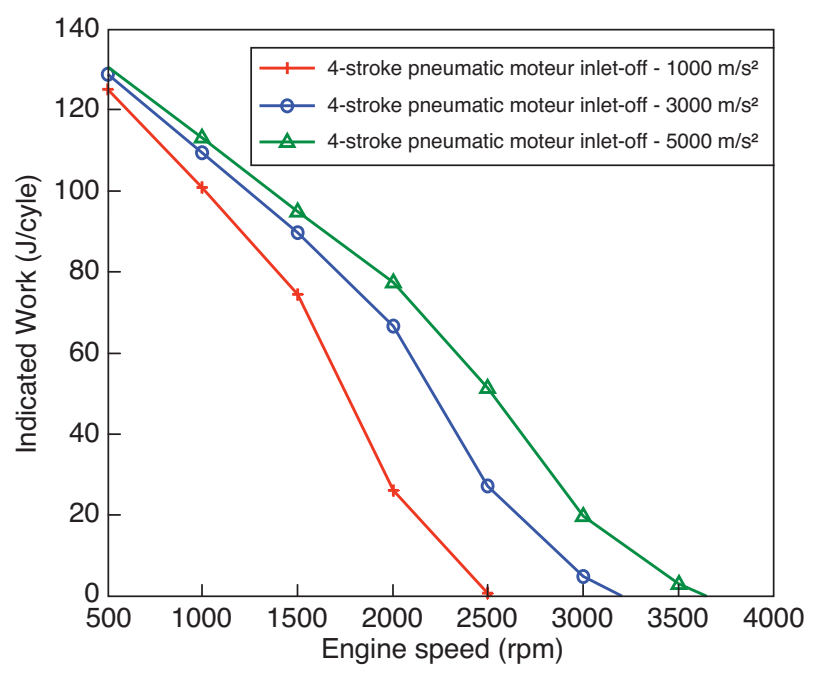

Figure 19

Indicated work $v s$ engine speed in 4-stroke pneumatic motor with inlet-off, with a charging valve max acceleration of 1000,3000 and $5000 \mathrm{~m} / \mathrm{s}^{2}$. head (as for a 2-stroke pump mode), leaves open the question of the economic viability and technical feasibility of this cycle.

As for the pneumatic pump mode, the effect the engine speed and charging valve maximum acceleration on the performance of the 4-stroke pneumatic motor mode with inlet-off has been studied. Results can be found in Figure 19. This figure leads to conclusions quite different than those found with Figure 14. A large loss of indicated work can be
TABLE 4

Pneumatic motor mode results

\begin{tabular}{l|c|c|c}
\hline & 4-stroke & $\begin{array}{c}\text { 4-stroke } \\
\text { inlet-off }\end{array}$ & $\begin{array}{c}\text { 2-stroke } \\
\text { full variable }\end{array}$ \\
\hline Indicated work (J/cycle) & 74.6 & 94.80 & 76.26 \\
\hline Consumed air mass (g/cycle) & 0.983 & 0.767 & 0.547 \\
\hline $\mathrm{PME} \mathrm{(J/g)}$ & 75.9 & 123.4 & 139.3 \\
\hline
\end{tabular}


observed for any value of the charging valve acceleration as soon as an engine reaches a speed of 1500 RPM.

Therefore, for optimum fuel saving, the pneumatic motor mode should only be used to start and drive the vehicle at low speed [5].

\section{CONCLUSION}

In this paper, idealized cycles of pneumatic motor and pneumatic pump mode, for 2-stroke, 4-stroke and 4-stroke with one camshaft off have been presented. Numerical simulations with a quasi dimensional model, including a kinematic model of the charging valve have been conducted, in order to evaluate their performances. Three important conclusions have been drawn from simulation results:

- the valve train acceleration is the key to best performance for pneumatic cycles, especially for the pump mode. For higher maximum valve accelerations, the range where pneumatic modes can be used with high efficiency is extended;

- in the case of 4-stroke modes (motor and pump), it has been showed, that a benefit exists in using a disengagable inlet camshaft. Conversely, no benefit has been founded with a disengagable exhaust camshaft;

- in the case of 2-stroke fully variable modes, simulations have shown a slight benefit of using them. But the technical complications and the cost generated leave the question of the viability of these solutions open.

The performance of pneumatic hybrid modes highly depends on gas flow through the charging valve throat. So taking into account the charging valve kinematics is imperative, but not sufficient. Future work has to take into account the gas dynamics between the charging valve and the air tank through the pipe.

\section{REFERENCES}

1 Schechter M. (1999) New cycles for automobile engines, International Congress and Exposition, Detroit, Michigan.
2 Andersson M., Johansson B., Hultqvist A. (2005) An air hybrid for high power absorption and discharge, SAE Technical paper series 2005-01-2137.

3 Higelin P., Charlet A. (2001) Thermodynamic Cycles for a New Hybrid Pneumatic-Combustion Engine Concept, 5th International Conference on Internal Combustion Engines 2001, Naples.

4 Vasile I. (2005) Étude théorique et expérimentale d'un moteur hybride thermo-pneumatique, in Laboratoire Mécanique Énergétique, Orléans, p. 194.

5 Ivanco A. et al. (2008) Stratégies de gestion pour un moteur hybride pneumatique, CIFA 2008, Bucarest.

6 Tai C. et al. (2003) Using camless valvetrain for air hybrid optimization, SAE Technical paper series 2003-01-0038.

7 Trajkovic S., Tunestal P., Johansson B. (2008) Investigation of Different Valve Geometries and Valve Timing Strategies and their Effect on Regenerative Efficiency for a Pneumatic Hybrid with Variable Valve Actuation, SAE Technical paper series 2008-01-1715.

8 Battistoni M. et al. (2007) Development of an Electro-Hydraulic Camless VVA System, International Congress and Exposition 2007, SAE: Capri, Naples, Italy.

9 Durrieu D., Picron V., Frederic A. (2008) Electro-Magnetic Valve Actuation System: First Steps Toward Mass Production, SAE Technical paper series 2008-01-1360.

10 Trajkovic S. et al. (2006) FPGA Controlled Pneumatic Variable Valve Actuation, SAE Technical paper series 2006-01-0041.

11 Trajkovic S. et al. (2007) Introductory study of variable valve actuation for pneumatic hybridization, SAE Technical paper series 2007-01-0288.

12 Wiebe (1970) Brennverlauf und Kreisprozess von Verbrennungsmotoren, VEB Verlag Technik.

13 Woshni G.A. (1967) Universally application equation for instantaneous heat transfer coefficient in internal combustion engine, SAE 76, 670931, 3065-3083.

Final manuscript received in April 2009 Published online in September 2009 